\title{
Stress and overeating
}

\section{Opinion}

It's been a busy and stressful day. I turned on the television and grab a packet of potato chips during my mid-evening break and I didn't notice that it was extra-large. My initial plan was to just take few ones but before I know it, I have finished with whole thing....At the end I was feeling better and relaxed.......so it was a start of my emotional eating behavior leading towards over eating. ${ }^{1,2}$

Stress is a modern poison that is making us fat, bald, crazy and extremely unhealthy. In the short term, stress can shut down appetite but if it persists-it's a different story. Three stress hormones our destroying our body. In a healthy stress state these hormones release according to individual demands and fall rapidly once it is dealt with but the prolonged exposure of theses hormones particularly CORTISOL in chronic stress state, adversely affecting our hunger, immune and central nervous system..$^{3-5}$

Numerous studies showed that physical and emotional distress increases the intake of high sugary and high fatty foods in personal preferences list.These foods in this condition served as COMFORT FOODS for these people. High cortisol level in combination of high insulin levels increases one's appetite including motivation towards eating. These hormones also contribute fat deposition around the waist line. That's why two indicators of chronic stress: low socioeconomic status and job pressures have been strongly associated with abdominal obesity. Some studies show a significant role of Ghrelin a hunger hormone in it also. There is a mark Gender difference in Stress coping behavior, as women are more likely to turn to foods and men towards alcohol and smoking. ${ }^{1,6,7}$

Stress also slows down our will power to go for healthy life style. Over eating along with sedentary life style and sleep disturbances as stress related behaviors contribute to Obesity. ${ }^{8,9}$ When we are hurried and under stress, we tend to make poor food and nutritional choices which adds up more stress in our life in the long run. Some of the faulty dietary habits are as follows:
a. Binging on Fast foods and candies
b. Skipping breakfast
c. Mindless munching
d. Inadequate water intake
e. Excess caffeine consumption
f. Late night snaking

Eventually, these habits lead to Obesity problem, people usually go for different Crash diets to reduce their excessive weight and some suffer from eating disorders. These all behaviors and choices are actually emotional decisions lead us towards unhealthy life patterns with poor health outcomes. We can cope with our anxiety with healthy and nutritional strategies to win the battle of obesity and overeating. Some of these are following. ${ }^{2,10}$
i. Don't skip meals especially breakfast
ii. Take small frequent meals ideally after every $4-5$ hours

Volume 3 Issue 5 - 2015

\author{
Maria Nadeem \\ University of the Punjab, Pakistan
}

Correspondence: Maria Nadeem, Clinical Nutritionist and Dietician, University of the Punjab, 388-Rblock, Johar Town Lahore, Pakistan, Tel 0321482224I,

Email marianadeem2007@hotmail.com

Received: December 16, 2015 | Published: December 29, 2015

iii. Get enough sleep 7-8hours a day as sleep cycle controls Leptin and ghrelin hormone.

iv. Watch your sugar intake in your daily menu items and monitor your blood sugar level on weekly basis.

v. Add more fruits and vegetables in your diet and try new and different recipes of them.

vi. Add more whole grains as a source of fiber as it helps in fullness and overeating is discouraged.

vii. Go for nuts, seeds, fish in daily menus as good sources of MUFA and PUFA, providing essential fats for human brain.

viii. Try to make combination of raw and cooked foods as it improves serotonin level and decrease cortisol level.

ix. Quit all kinds of refined products and whole dairy as it also imbalance certain hormones

x. Go for low fat substitutes in dairy and meat products

xi. Don't go for excessive smoking and alcohol consumption to cope with stress.

xii. Think positive and stay determined. ${ }^{4,11-13}$

\section{Acknowledgements}

None.

\section{Conflict of interest}

The author declares no conflict of interest.

\section{References}

1. Vicennati V, Pasqui F, Cavazza C, et al. Stress-Related Development of Obesity and Cortisol in Women. Obesity. 2009;17(9):1678-1683.

2. http://www.psychologicalscience.org/index.php/publications/ observer/2011/december-11/stress-hurts-our-minds-and-our-bodies. html

3. Melanie Greenberg. Why we gain weight when we are stressed-and how not to. Psychology today. 2013.

4. Spencer SJ, Tilbrook A. The Glucocorticoid Contribution to Obesity. Stress. 2011;14(3):233-246. 
5. Mathes WF, Brownley KA, Mo X, et al. The Biology of Binge Eating Appetite. 2009;52(3):545-553.

6. Adams CE, Greenway FL, Brantley PJ. Lifestyle Factors and Ghrelin: Critical Review and Implications for Weight Loss Maintenance. Obes Rev. 2011;12(5):e211-e218.

7. Manzoni GM, Pagnini F, Gorini A, et al. Can Relaxation Training Reduce Emotional Eating in Women with Obesity? An exploratory study with 3 months of follow-up. J Am Diet Assoc. 2009;109(8):1427-1432.

8. Finch LE, Tomiyama AJ. Comfort eating, psychological stress and depressive symptoms in young adult women. Appetite. 2015;95:239244 .
9. Oswal A, Yeo G. Leptin and the control of body weight: a review of its diverse central targets, signaling mechanisms and the role in the pathogenesis of Obesity. Obesity. 2010;18(2):221-229.

10. Duyff RL. Your healthy weight: Key to wellness. In: Hoboken NJ, editor. American Dietetic Association Complete Food and Nutrition Guide. 4th ed. John Wiley \& Sons; 2012.

11. Emotional eating. American Academy of Pediatrics.

12. Stop the cravings! Eat right! Academy of Nutrition and Dietetics. 2014.

13. Macht M. How emotions affect eating: A five-way model. Appetite. 2008;50(1):1-11. 